\title{
Organochlorine Pesticides in Soils Around Watersheds of Beijing Reservoirs: A Case Study in Guanting and Miyun Reservoirs
}

\author{
Wenyou Hu · Yonglong Lu $\cdot$ Guang Wang · \\ Tieyu Wang · Wei Luo · Yajuan Shi • \\ Xiang Zhang · Wentao Jiao
}

Received: 1 June 2008/Accepted: 26 February 2009/Published online: 12 March 2009

(C) Springer Science+Business Media, LLC 2009

\begin{abstract}
A systematic survey of organochlorine pesticides (OCPs) residues in soils around reservoirs that supply water to Beijing, China, has been lacking. 104 representative surface soil samples were collected around Guanting Reservoir (GTR) and Miyun Reservoir (MYR) in Beijing watershed to characterize concentrations and sources of organochlorine pesticides, hexachlorocyclohexane $(\mathrm{HCH})$ and dichlorodiphenyltrichloroethane (DDT). Compared with other studies of OCPs in soils and with the Chinese environmental quality standard for soil, the concentrations of OCP were relatively lower in soils around the watershed. The results indicated that past agricultural application of OCPs was the major source of OCP residues in the watershed.
\end{abstract}

Keywords Organochlorine pesticides .

Soil contamination - Sources - Watershed

Organochlorine pesticides (OCPs) such as $\mathrm{HCH}$ and DDT are ubiquitous environmental contaminants, which have been extensively used throughout the world in agriculture, forestry, and public health (Singh 2001; Kannan et al. 2004). Occurrence of OCPs in the environment is a public health concern because of their persistence, long-range

W. Hu · Y. Lu (ه) · G. Wang - T. Wang - W. Luo · Y. Shi ·

$\mathrm{X}$. Zhang $\cdot$ W. Jiao

State Key Laboratory of Urban and Regional Ecology,

Research Center for Eco-Environmental Sciences,

Chinese Academy of Sciences, Beijing 100085, China

e-mail: yllu@rcees.ac.cn

W. Hu $\cdot$ Y. Lu $\cdot$ G. Wang $\cdot$ X. Zhang $\cdot$ W. Jiao Graduate School of Chinese Academy of Sciences, Beijing 100039, China transport, bioaccumulation as well as potential toxic effects on humans and wildlife. China is a major agricultural producer and OCPs were the primary pesticides produced and used in China from the 1960s to the 1980s. Although $\mathrm{HCH}$ and DDT have been officially banned or restricted in China since 1983, their persistence has left residual amounts detected in soils from many areas in China (Gao et al. 2008). HCH and DDT residues in soil can enter the waterbodies and reservoirs through percolation, leaching and surface run-off polluting the surface water as well as producing complex effects on the aquatic environments $(\mathrm{Fu}$ et al. 2003; Bidleman and Leone 2004). Therefore, soil ecosystem around watershed plays an important role in storage, transport, and cycling of OCPs in the soil-water interaction zone.

In Beijing, water is mainly supplied from Guanting Reservoir (GTR) and Miyun Reservoir (MYR). Agriculture is a major land use in the watershed of the two reservoirs, where corn and cash crops are mainly cultivated. GTR is Beijing's second largest source of water for agricultural and industrial purposes, and historically, it was also used for drinking water supply until 1997. Since then, however, industrial pollution and contamination from farming have substantially degraded the quality of water in this reservoir (Xue et al. 2006; Wang et al. 2007). MYR is the largest water source for Beijing, also the largest reservoir in north China, and nearly all drinking water supply of Beijing comes from this reservoir. OCP residues have been studied in different soils of this area, but almost all attention was paid to assess the quality of soils surrounding GTR (Wang et al. 2005b, 2007). Data on OCP residues in soils surrounding MYR are scarce. Thus, there is an urgent need for thorough investigation and assessment of OCPs in soils around GTR and MYR as a whole. The present work was a large-scale and systematic investigation of OCPs in soils 
around the two watersheds of Beijing reservoirs. The main objectives of this study were to elucidate the residue levels, sources and affecting factors of OCPs in soils around the reservoirs, and to identify the differences in OCP concentrations in soils between GTR and MYR.

\section{Materials and Methods}

In May 2007, 104 soil samples including 60 samples around GTR and 44 samples around MYR were collected. The locations of the sampling sites are shown in Fig. 1. Intensive and systematic sampling surrounding the reservoirs was made to provide better understanding of the contamination patterns. Throughout the survey, a global positioning system (GPS) was used to locate the sampling sites. The sampling sites covered different types of land use patterns: orchards, farmlands and fallow areas. Each sample was made from a mixture of five subsamples collected from five spots of an area of about $100 \times 100 \mathrm{~m}^{2}$ (at the four corners and the center). All soil subsamples were collected at a depth of $0-20 \mathrm{~cm}$ using a stainless steel shovel. Grass and other sundries were removed from the surface of each sample location before the sample was collected. The soil samples were air dried at room temperature $\left(22-25^{\circ} \mathrm{C}\right)$ for about 15 days, sieved to $<2 \mathrm{~mm}$, and stored at $4^{\circ} \mathrm{C}$ in pre-cleaned glass jars until analysis. The sampling scheme took into account of sites representing the most relevant characteristics of the watersheds and soil types.

For extraction of pesticides from the soil, n-hexane and dichloromethane (J. T. Baker, HPLC) were used. Anhydrous sodium sulfate (analytical grade) and silica gel (60 mesh, for column chromatograph) were activated at $180^{\circ} \mathrm{C}$ for $24 \mathrm{~h}$. Solid phase extraction (SPE, $6 \mathrm{~mL}$, Supelco, Bellefonte, PA, USA) cartridges containing $1 \mathrm{~g}$ of florisil was washed with $10 \mathrm{~mL}$ of $\mathrm{n}$-hexane before use. A mixture of standard solution containing $\alpha-, \beta-, \gamma-, \delta-\mathrm{HCH}$ isomers, $p, p^{\prime}$-DDE, $p, p^{\prime}$-DDD, $o, p^{\prime}$-DDT, and $p, p^{\prime}$-DDT at $1 \mathrm{mg} / \mathrm{g}$ per compound was obtained from the National Research Center for Certified Reference Materials of China. The amount of substance in the extracts was quantified using the internal standard (2,4,5,6-tetrachloro-m-xylene or TCMX) supplied by Supelco (Supelco, Bellefonte, PA, USA). Agilent6890 gas chromatograph (GC) equipped a ${ }^{63} \mathrm{Ni}$ electron capture detector ( $\mu \mathrm{ECD}$ ) (Agilent Technologies, Wilmington, DE, USA) was used for the analysis. The column used was HP-5 silica capillary column with $30 \mathrm{~m} \times 0.32 \mathrm{~mm}$ i.d $\times 0.25 \mu \mathrm{m}$ film thickness.

Soil sample $(5.0 \mathrm{~g}$ dry weight) was mixed with $1 \mathrm{~g}$ anhydrous sodium sulfate. One milliliter of 2,4,5,6-tetrachloro-m-xylene at the concentration of $0.08 \mu \mathrm{g} / \mathrm{mL}$ was added. The mixture was extracted twice with $35 \mathrm{~mL}$ of hexane/dichloromethane $(1: 1, \mathrm{v} / \mathrm{v})$ by ultrasonication for $60 \mathrm{~min}$ and then centrifuged. Extracts were concentrated to about $2 \mathrm{~mL}$ by rotary evaporation, and further purified with SPE cartridges loaded with $1 \mathrm{~g}$ silica gel and $1 \mathrm{~g}$ anhydrous sodium sulfate. The elution was subsequently carried out using $20 \mathrm{~mL}$ of hexane/dichloromethane $(7: 3, \mathrm{v} / \mathrm{v})$. The eluant was concentrated to a final volume of $1 \mathrm{~mL}$ for GC analysis. Reagent blanks were also analyzed simultaneously with the experimental samples. Meanwhile, several grams of soil were dried for $8 \mathrm{~h}$ at $80^{\circ} \mathrm{C}$ to obtain moisture content data.

The purified extract was analyzed using $\mathrm{GC}-\mu \mathrm{ECD}$ under splitless injection mode with ultrapure nitrogen as the carrier gas and the make-up gas. The injector and detector temperatures were 220 and $300^{\circ} \mathrm{C}$, respectively. The oven temperature was initially set at $100^{\circ} \mathrm{C}$ with a 2-min hold, ramped at $10^{\circ} \mathrm{C} / \mathrm{min}$ to $160^{\circ} \mathrm{C}$ with a 2 -min hold, $4^{\circ} \mathrm{C} / \mathrm{min}$ to $230^{\circ} \mathrm{C}$ with a 5 -min hold, $10^{\circ} \mathrm{C} / \mathrm{min}$ to $270^{\circ} \mathrm{C}$ with a 2 -min hold. OCPs were identified by
Fig. 1 Study area and soil sampling locations around watersheds of two reservoirs in Beijing

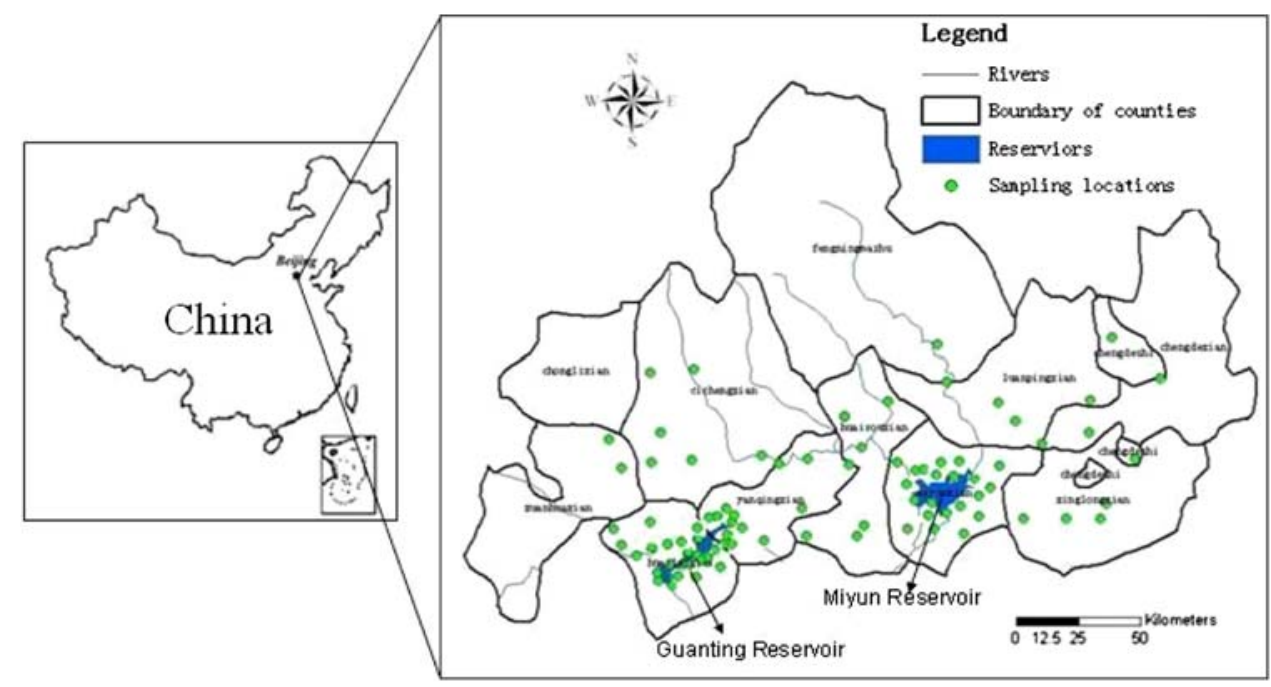


retention time matched to standards and were quantified using peak area integration. OCPs measured include four DDT homologues and four $\mathrm{HCH}$ isomers. Concentration of $\sum$ DDT and $\sum \mathrm{HCH}$ were the sum of the four DDT homologues and four $\mathrm{HCH}$ isomers, respectively. The OCP concentrations in soil are reported on a dry weight basis.

For quality assurance and quality control, procedural blanks and matrixes spiked with the standard solution were analyzed. None of the target compounds were detected in the procedural blanks. All solvents used were distilled in glass (PR grade) and were checked for interferences or contamination prior to use. The recoveries of OCPs spiked to soil ranged from $73.3 \%$ to $96.2 \%(\mathrm{n}=3)$. Extraction efficiency, as indicated by recovery of the surrogate standards (TCMX), was $75 \pm 10 \%$. The limits of detection (LOD) were described as three times of signal-to-noise ratio $(\mathrm{S} / \mathrm{N})$. The detection limit ranged from 0.05 to $0.24 \mathrm{ng} \mathrm{g}^{-1}$. GC analysis was repeated twice for each replicate sample and the relative standard deviation (RSD) of replicate analyses was less than $10 \%$.

Total organic carbon (TOC) was analyzed using an Universal CHNOS Elemental Analyzer (Elementar Vario EL III, Germany), $\mathrm{pH}$ was measured using a soil: water ratio of $1: 2.5$ by a potentiometric glass electrode (Wang et al. 2007). The software used for mapping the sampling sites was ArcGis (ESRI, US). SPSS 11.5 for windows was employed for statistical analysis. Correlation analysis was used to explore the relationship between OCPs and selected soil properties.

\section{Results and Discussion}

The range, mean, and median concentrations of OCPs and selected soil properties around the watersheds of Beijing water reservoirs are shown in Table 1. Concentrations of $\mathrm{HCH}$ in soils reported for Beijing and other areas in the literature are listed in Table 2. The mean concentration of total $\mathrm{HCH}$ was $0.67 \mathrm{ng} \mathrm{g}^{-1}$, ranging from $\mathrm{ND}$ to $5.56 \mathrm{ng} \mathrm{g}^{-1}$. In comparison with $\mathrm{HCH}$ concentrations in soils from Beijing and other areas in China, the mean concentration in soils was slightly lower than that reported earlier for GTR, and was also lower than the residual levels reported for Tibet plateau, Pearl River Delta, Hong Kong, Tianjin, Nanjing and other areas of Beijing. However, the concentration was slightly higher than that reported for Taihu Lake Region, China. Compared with the concentrations of HCHs in overseas soils, the concentration was also lower than those reported for Central Germany, Romania, Vietnam and India (Table 2).

According to the guidelines of Chinese environmental quality standards for soil (GB 15618-1995), the limits for $\sum \mathrm{HCH}$ in the soils are 50,500 and $1,000 \mathrm{ng} \mathrm{g}^{-1}$,
Table 1 Concentrations $\left(\mathrm{ng} \mathrm{g}^{-1}\right)$ of OCPs and selected properties in soils around Beijing watershed

\begin{tabular}{cccllll}
\hline & Mean & SD & Minimum & Maximum & Median & $\begin{array}{l}\text { Detection } \\
\text { rate }(\%)\end{array}$ \\
\hline$\alpha-\mathrm{HCH}$ & 0.01 & 0.04 & $\mathrm{ND}$ & 0.27 & 0.00 & 11 \\
$\beta$-HCH & 0.46 & 0.75 & $\mathrm{ND}$ & 4.58 & 0.28 & 59 \\
$\gamma-\mathrm{HCH}$ & 0.14 & 0.17 & $\mathrm{ND}$ & 1.01 & 0.12 & 62 \\
$\delta$-HCH & 0.05 & 0.21 & $\mathrm{ND}$ & 1.53 & 0.00 & 11 \\
$\sum \mathrm{HCH}$ & 0.67 & 0.95 & $\mathrm{ND}$ & 5.56 & 0.40 & 84 \\
$p, p^{\prime}-$ & 3.11 & 8.61 & $\mathrm{ND}$ & 78.1 & 0.78 & 82 \\
DDE & & & & & & \\
$p, p^{\prime}-$ & 0.16 & 0.65 & $\mathrm{ND}$ & 5.71 & 0.00 & 17 \\
DDD & & & & & & \\
$o, p^{\prime}-$ & 0.59 & 1.58 & $\mathrm{ND}$ & 9.04 & 0.00 & 35 \\
DDT & & & & & & \\
$p, p^{\prime}-$ & 2.72 & 6.65 & $\mathrm{ND}$ & 50.7 & 0.97 & 91 \\
DDT & & & & & & \\
$\sum \mathrm{DDT}$ & 6.64 & 15.3 & $\mathrm{ND}$ & 117 & 1.91 & 93 \\
Ratio 1 & 0.04 & 0.13 & 0.00 & 0.73 & 0.00 & \\
Ratio 2 & 1.00 & 1.10 & 0.00 & 5.49 & 0.64 & \\
TOC(\%) & 1.68 & 0.74 & 0.35 & 3.74 & 1.63 & \\
pH & 7.56 & 0.35 & 6.84 & 8.16 & 7.60 & \\
\hline
\end{tabular}

a Mean, SD, minimum and maximum were calculated assuming nondetect (ND) measurements were equal to zero for statistical purpose

b Ratio $1=\alpha-\mathrm{HCH} / \gamma-\mathrm{HCH} ;$ Ratio $2=\left(p, p^{\prime}-\mathrm{DDE}+p, p^{\prime}-\mathrm{DDD}\right) /$ $p, p^{\prime}$-DDT

c $\sum \mathrm{HCH}=\alpha-\mathrm{HCH}+\beta-\mathrm{HCH}+\gamma-\mathrm{HCH}+\delta-\mathrm{HCH}, \sum \mathrm{DDT}=p, p^{\prime}-$ $\mathrm{DDE}+p, p^{\prime}-\mathrm{DDD}+o, p^{\prime}-\mathrm{DDT}+p, p^{\prime}-\mathrm{DDT}$

corresponding to Class I, II and III, respectively. The total concentrations of $\sum \mathrm{HCH}$ in all soil samples were within the limit of Class I. Although the concentrations of $\mathrm{HCH}$ were not high enough to cause acute effects, they could have negative impacts on the local atmosphere and aquatic ecosystems in a long term, especially for several sites with higher concentrations of $\mathrm{HCH}$. $\mathrm{HCH}$ has much higher water solubility, vapor pressure, and higher Henry's Law Constant than DDT. In this regard, $\mathrm{HCH}$ presents an easier ability to degrade and transfer from soil to liquid and atmosphere (Shi et al. 2005). Therefore, the ecological and health effects of these substances through food chain at the relatively lower concentrations still need further attention in light of their possible biological magnifications in higher trophic organisms including human beings (Zhang et al. 2006).

Technical $\mathrm{HCH}$ and lindane were two types of $\mathrm{HCH}$ products manufactured and used in China. Technical $\mathrm{HCH}$ contains about $55-80 \% \alpha-\mathrm{HCH}, 5-14 \% \quad \beta-\mathrm{HCH}, 8-15 \%$ $\gamma-\mathrm{HCH}$ and minor proportions of other isomers (Kannan et al. 2003), lindane contains $>99 \% \gamma-\mathrm{HCH}$. Therefore, the ratio of $\alpha-\mathrm{HCH} / \gamma-\mathrm{HCH}$ can be an indicator that reflects the different sources of HCHs. A high ratio of $\alpha-\mathrm{HCH} / \gamma-\mathrm{HCH}$ in the soil indicates the input of technical $\mathrm{HCH}$ and a low 
Table 2 Comparison of HCHs and DDTs in soils from Beijing and other areas (ng g $\left.{ }^{-1} \mathrm{dw}\right)$

\begin{tabular}{|c|c|c|c|c|c|c|}
\hline Locations & Land uses & $\mathrm{N}$ & $\begin{array}{l}\text { Sampling } \\
\text { date }\end{array}$ & $\sum \mathrm{HCH}$ & $\sum \mathrm{DDT}$ & References \\
\hline Beijing, China & $\begin{array}{l}\text { Soil around guanting } \\
\text { Reservoir }\end{array}$ & 56 & 2003 & $\begin{array}{l}\text { ND-7.33 } \\
0.69 \text { (mean) }\end{array}$ & $\begin{array}{l}\text { ND-76.01 } \\
9.46 \text { (mean) }\end{array}$ & Wang et al. (2005a) \\
\hline Beijing, China & Orchard soil & 17 & 2003 & $\begin{array}{l}2-760.3 \\
32 \text { (median) }\end{array}$ & $\begin{array}{l}\text { 7.2-2910 } \\
381.3 \text { (median) }\end{array}$ & Shi et al. (2005) \\
\hline Beijing, China & Urban soil & 30 & 2003 & $\begin{array}{l}1.83-48.83 \\
7.53 \text { (mean) }\end{array}$ & $\begin{array}{l}7.24-244.37 \\
56.78 \text { (mean) }\end{array}$ & Li et al. (2005) \\
\hline Beijing, China & Outskirts soil & 47 & 2004 & $\begin{array}{l}1.36-56.61 \\
5.25 \text { (median) }\end{array}$ & $\begin{array}{l}0.77-2178.56 \\
38.66 \text { (median) }\end{array}$ & Cai et al. (2008) \\
\hline Tianjin, China & Urban and rural soil & 188 & 2001 & $\begin{array}{l}1.3-1095 \\
45.8 \text { (mean) }\end{array}$ & $\begin{array}{l}0.7-972.2 \\
56.0 \text { (mean) }\end{array}$ & Cai et al. (2008) \\
\hline Nanning, China & Agricultural soil & 158 & 2002 & $\begin{array}{l}2.7-130.6 \\
13.6 \text { (mean) }\end{array}$ & $\begin{array}{l}63-1050.7 \\
64.1 \text { (mean) }\end{array}$ & Cai et al. (2008) \\
\hline Tibet, China & Soil in pristine areas & 15 & 1993 & $\begin{array}{l}0.18-5.38 \\
1.97 \text { (mean) }\end{array}$ & $\begin{array}{l}\text { ND-2.83 } \\
1.13 \text { (mean) }\end{array}$ & Fu et al. (2001) \\
\hline $\begin{array}{l}\text { Pearl River } \\
\text { Delta, China }\end{array}$ & Crop soil & 37 & 2002 & $\begin{array}{l}0.05-24.1 \\
2.94 \text { (median) }\end{array}$ & $\begin{array}{l}0.52-414 \\
20.1 \text { (median) }\end{array}$ & Li et al. (2006a) \\
\hline Hong Kong, China & Surface soil & 46 & 2000 & $\begin{array}{l}2.5-11 \\
6.19 \text { (mean) }\end{array}$ & $\begin{array}{l}\text { ND-5.7 } \\
0.52 \text { (mean) }\end{array}$ & Zhang et al. (2006) \\
\hline Taihu Lake Region, China & Paddy soil & 10 & 1999 & ND-3.4 & ND-5.3 & Cai et al. (2008) \\
\hline Central Germany & Agricultural soils & 11 & 1995 & $\begin{array}{l}4.60-11.50 \\
7.52 \text { (mean) }\end{array}$ & $\begin{array}{l}23.7-173 \\
72.0 \text { (mean) }\end{array}$ & Cai et al. (2008) \\
\hline Romania & Surface soil & 46 & 2000 & $\begin{array}{l}0.7-90 \\
16 \text { (mean) }\end{array}$ & $\begin{array}{l}3.5-1542 \\
537 \text { (mean) }\end{array}$ & Cai et al. (2008) \\
\hline Hanoi, Vietnam & Agricultural soil & 31 & 2006 & $\begin{array}{l}0.05-20.57 \\
8.03 \text { (mean) }\end{array}$ & $\begin{array}{l}0.02-171.83 \\
89.86 \text { (mean) }\end{array}$ & Toan et al. (2007) \\
\hline Dehradun, India & Paddy soil & 10 & 2001 & $\begin{array}{l}122-638 \\
326 \text { (mean) }\end{array}$ & $\begin{array}{l}13-238 \\
117 \text { (mean) }\end{array}$ & Babu et al. (2003) \\
\hline Beijing, China & Soil around watershed & 104 & 2007 & $\begin{array}{l}\text { ND-5.56 } \\
0.67 \text { (mean) }\end{array}$ & $\begin{array}{l}\text { ND-116.74 } \\
6.64 \text { (mean) }\end{array}$ & This study \\
\hline
\end{tabular}

ratio indicates the use of lindane (Toan et al. 2007; Cai et al. 2008).

The mean percentages of $\mathrm{HCH}$ isomers in soils were as follows: $\beta$-HCH $>\gamma-\mathrm{HCH}>\delta$-HCH $>\alpha-\mathrm{HCH}$. Comparing to $\alpha-\mathrm{HCH}$, relatively high proportion of $\beta$ - $\mathrm{HCH}(69 \%$ of $\sum \mathrm{HCHs}$ ) was detected in this study, confirming that the technical $\mathrm{HCH}$ has not been used in this region recently. This also suggests persistence and environmental stability of $\beta-\mathrm{HCH}$ in the environment. The predominance of $\beta$ - $\mathrm{HCH}$ among $\mathrm{HCH}$ in most soil samples suggested that they were from historical contamination rather than recent input (Toan et al. 2007). The mean ratio of $\alpha-\mathrm{HCH} / \gamma-\mathrm{HCH}$ was 0.04 with a maximum of 0.73 , and the ratios were zero in $90 \%$ of the samples, which were much lower than the $\alpha / \gamma-\mathrm{HCH}$ ratio found in technical $\mathrm{HCH}$ mixture, possibly indicating a input of lindane in the past several years or more $\alpha-\mathrm{HCH}$ evaporated into atmosphere from soil with time (Gao et al. 2008). The use of HCHs in agriculture was restricted since 1983 in China, but the use of lindane may have been continued for several years in pest control in the past (Fu et al. 2003). According to a study on concentrations of extractable organohalogens in $\mathrm{PM}_{2.5}$ and $\mathrm{PM}_{10}$ in Beijing, China, $\beta$-HCH accounted for $69 \%-84 \%$ and $56 \%-$ $85 \%$ of $\sum \mathrm{HCHs}$, respectively (Xu et al. 2005), which were similar to the same ratios found in soils around GTR and MYR. This suggested that HCHs in soil and air around our study area have similar sources, and the residue levels were a reflection of air-soil equilibrium.

With regard to DDTs, high concentrations were detected in soils around the two reservoirs, which accounted for about $90 \%$ of the total OCP concentrations. The mean concentration of total DDT was $6.64 \mathrm{ng} \mathrm{g}^{-1}$, and ranged from $\mathrm{ND}$ to $117 \mathrm{ng} \mathrm{g}^{-1}$. In comparison with the soils studied around Beijing and other regions in China, DDT levels in this area were higher than those of soils in pristine areas of Tibet plateau, Hong Kong, and Taihu Lake, but 
were significantly lower than those of other regions listed in Table 2. It turns out that the concentrations of DDT in the soils around Beijing watersheds appeared to be moderate as compared with other places of Beijing.

According to the guidelines of Chinese environmental quality standard (GB 15618-1995), the limits for $\sum D D T$ in the soils are 50,500 and $1,000 \mathrm{ng} \mathrm{g}^{-1}$, corresponding to Class I, II and III, respectively. The levels of $\sum$ DDT in 101 samples were below the criteria for Class I, and those in 3 samples were above the criteria for Class I but below the criteria for Class II. The highest DDT concentrations were all found in soils around the GTR. According to our recent survey, OCPs (such as lindane and dicofol) had been used on crops in this region in the past several years, although these pesticides are not used recently. This implies that the present DDT residues in soils were mainly from the historical application of OCPs.

Technical DDT and dicofol were the main sources of DDT pollution in China. Technical DDT is typically composed of $77.1 \% p, p^{\prime}$-DDT, $14.9 \% o, p^{\prime}$-DDT, $4 \% p, p^{\prime}$ DDE and some other trace impurities, while dicofol contains about 3-7\% DDTs as impurities. The environmental input of DDT caused by applying technical DDT mixture and dicofol has been studied to develop strategies for elimination in China (Shi et al. 2005). DDT metabolites have a long persistence in environment and gradually biodegrade to DDE under aerobic conditions and to DDD under anaerobic conditions. Since the level of DDT in the natural environment will decrease with time and the major metabolites are expected to be DDE and DDD, the ratio of $\left(p, p^{\prime}\right.$-DDE $+p, p^{\prime}$-DDD $) / p, p^{\prime}$-DDT can be used as an indicator of resident time of $p, p^{\prime}$-DDT in the environment (Qiu et al. 2004). The ratio of $>1$ is normally expected for aged mixtures in the environment and $<1$ indicated the relatively recent exposure to parent DDT (Jaga and Dharmani 2003).

The mean composition of DDT compounds in soils was as follows: $p, p^{\prime}$-DDE $>p, p^{\prime}$-DDT $>o, \quad p^{\prime}$-DDT $>p, p^{\prime}-$ DDD, with the $p, p^{\prime}$-DDE accounted for a major composition of DDT (48\% of $\sum$ DDT). This indicated that the soil contamination by DDT occurred in the past and significant aerobic degradation of DDT had occurred in soils. During the dry season, with aerobic soil conditions, the active oxidative transformation of $p, p^{\prime}$-DDT to $p, p^{\prime}$-DDE was expected (Toan et al. 2007). The higher concentration of DDE found in this area was also probably related to the longer persistence of DDE than those of DDD and the parent compound DDT. The ratio of $\left(p, p^{\prime}-\mathrm{DDE}+p, p^{\prime}-\right.$ DDD) $/ p, p^{\prime}$-DDT was $<1$ in $63 \%$ of the soil samples, and high proportion of $p, p^{\prime}$-DDT ( $41 \%$ of $\sum \mathrm{DDT}$ ) indicated a recent input of DDT occurred at some sampling locations. Considering that DDT is the major impurity of dicofol, the recent input of DDT in soils at some sites may be related to the agricultural use of dicofol in this region in past several years. Interestingly, high concentrations of $p, p^{\prime}$-DDT were also observed in air above Beijing $\left(20.4 \mathrm{pgm}^{-3}\right.$ in $\mathrm{PM}_{2.5}$ and $11.2 \mathrm{pgm}^{-3}$ in $\mathrm{PM}_{10}$ ), and were also ascribed to illegal application of technical DDT and the use of dicofol in the surrounding region (Xu et al. 2005). Overall, our results suggest that the DDT pollution in soils in our study area was a mixture pollution of historical application of technical DDT and agricultural use of dicofol in past several years.

Because OCP in soils around the reservoirs in Beijing are mainly from historical sources, different land uses pattern and the establishment of farmland protection strategies (Harner et al. 1999; Shi et al. 2005) around these watersheds may contributed to differences in concentrations of OCP in soils around GTR and MYR (Fig. 2). Higher concentrations of OCPs in soils around GTR than in MYR suggest a larger amount or a longer use of OCPs in the area around the GTR. From the 1960s to the 1980s, large amounts of agrochemicals were applied to the agricultural areas around the GTR, to improve crop yields (Xue et al. 2006; Wang et al. 2007). The high OCP residues were almost found in soils collected from orchards, which showed that agricultural application of OCPs was the major source of this residue. In the GTR area, orchard lands account for $50 \%$ of the total land uses, while in the MYR area, orchard land account only for $20 \%$ of the total land uses. Orchard soils were likely to contain high concentrations of OCPs from the past application, because orchard
Fig. 2 Comparison of $\mathrm{HCH}$ and DDT concentrations in soils from GTR and MYR
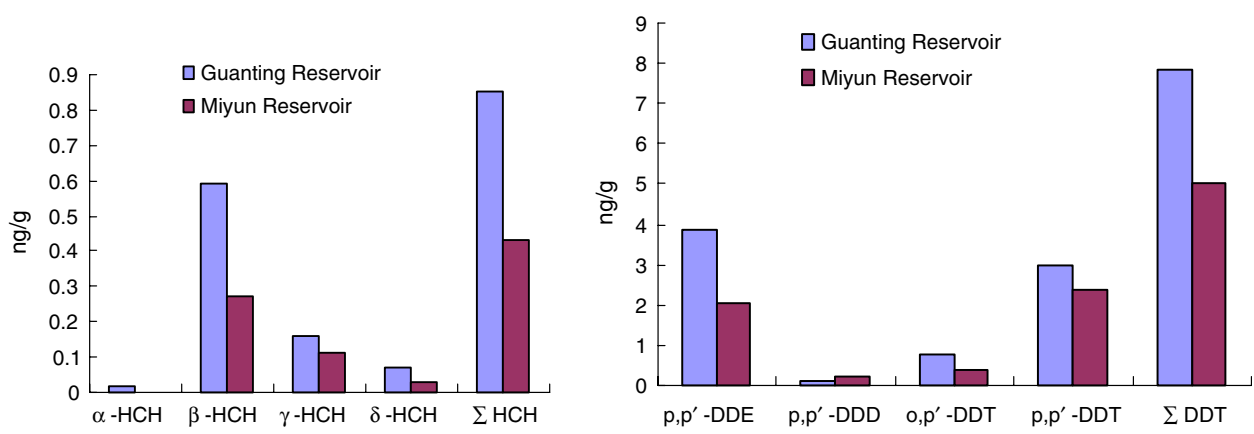
crops are high susceptibility to pests and diseases (Shi et al. 2005; Wang et al. 2005a).

OCPs are persistent hydrophobic contaminants and they may accumulate because of their resistance to biotic and abiotic degradation in environmental conditions. The contaminants in aquatic environments can directly affect biocommunities and may be transferred to higher trophic levels through the food chain. To better compare the discrepancy of HCHs and DDTs between GTR and MYR, we listed the concentrations of OCPs in water, sediment, and fish from the two reservoirs (Table 3). Concentrations of OCPs in water, sediment, and fish from GTR were also higher than those of MYR, which is consistent with this study on soils. The results indicated that though the levels of OCP were low in soils around the two reservoirs, these compounds can accumulate in fish and ultimately pose potential health risks to humans. Therefore, continual monitoring and further studies of OCPs in various environmental compartments, including biota and abiotic samples are needed to elucidate the trends, environmental behavior and ecological risks of OCP residues in the soils around the watershed.
Many factors can affect OCP residue levels in soils. TOC and $\mathrm{pH}$ were analyzed in soils to examine the relationship with $\mathrm{HCH}$ and DDT residues. The results of correlation analyses among OCPs, TOC, and $\mathrm{pH}$ are listed in Table 4. Significant positive correlations among a-HCH, $\beta$ - $\mathrm{HCH}, \gamma-\mathrm{HCH}$ and $\sum \mathrm{HCH}$ with TOC, and that between $\delta$ - $\mathrm{HCH}$ and $\mathrm{pH}$ were observed. The correlation between HCHs and TOC suggests binding of soil organic matter with OCPs (Zhu et al. 2005). On the other hand, the increase of organic matter content in soils can supply more carbon source to facilitate microbial degradation of OCPs (Wu et al. 1997). As a result, TOC content could affect the residue levels of OCPs in soils (Zhang et al. 2006). A correlation between $\mathrm{pH}$ with $\delta$ - $\mathrm{HCH}$ was found, but such relationships were not found for DDTs and other $\mathrm{HCH}$ isomers, indicating that soil $\mathrm{pH}$ have no obvious effect on DDT and $\mathrm{HCH}$ residues in the study area. Although the residue levels of DDT and $\mathrm{HCH}$ were different in the soils, a significant positive correlation was observed between $\sum \mathrm{HCH}$ and $\sum \mathrm{DDT}(p<0.01)$. This correlation probably showed that both HCHs and DDTs had similar sources and fate in the study area ( $\mathrm{Li}$ et al. 2006b). There were no

Table 3 Comparison of OCP concentrations in soil, water, sediment and fish between GTR and MYR

\begin{tabular}{|c|c|c|c|c|c|c|}
\hline & \multicolumn{2}{|c|}{ Guanting reservoir } & \multirow[t]{2}{*}{ Reference } & \multicolumn{2}{|c|}{ Miyun reservoir } & \multirow[t]{2}{*}{ References } \\
\hline & $\sum \mathrm{HCH}$ & $\sum \mathrm{DDT}$ & & $\sum \mathrm{HCH}$ & $\sum \mathrm{DDT}$ & \\
\hline Soil $\left(\operatorname{ng~g}^{-1}\right)$ & 0.85 & 7.84 & This study & 0.43 & 5.02 & This study \\
\hline Water $\left(n g \mathrm{~L}^{-1}\right)$ & 9.1 & 3.1 & Wang et al. (2003) & 2.48 & 0 & Cheng (2004) \\
\hline Sediment (ng $\mathrm{g}^{-1}$ ) & $0.28-10.8$ & $3.25-17.2$ & Xue et al. (2006) & - & - & \\
\hline Fish $\left(\mathrm{ng} \mathrm{g}^{-1}\right)$ & 4.32 & 15.69 & Sun et al. (2005a) & 0.09 & 2.25 & Sun et al. (2005b) \\
\hline
\end{tabular}

- , No data available

Table 4 Relationship between OCPs and selected soil properties

\begin{tabular}{|c|c|c|c|c|c|c|c|c|c|c|c|c|}
\hline & $\alpha-\mathrm{HCH}$ & $\beta-\mathrm{HCH}$ & $\gamma-\mathrm{HCH}$ & $\delta$-HCH & $\sum \mathrm{HCH}$ & $p, p^{\prime}-\mathrm{DDE}$ & $p, p^{\prime}-\mathrm{DDD}$ & $o, p^{\prime}$-DDT & $p, p^{\prime}-\mathrm{DDT}$ & $\sum D D T$ & TOC & $\mathrm{pH}$ \\
\hline$\alpha-\mathrm{HCH}$ & 1 & & & & & & & & & & & \\
\hline$\beta-\mathrm{HCH}$ & $0.40 * *$ & 1 & & & & & & & & & & \\
\hline$\gamma-\mathrm{HCH}$ & $0.59 * *$ & $0.47 * *$ & 1 & & & & & & & & & \\
\hline$\delta-\mathrm{HCH}$ & $0.52 * *$ & $0.26^{* *}$ & $0.32 * *$ & 1 & & & & & & & & \\
\hline$\sum \mathrm{HCH}$ & $0.58 * *$ & $0.95^{* *}$ & $0.64 * *$ & $0.51 * *$ & 1 & & & & & & & \\
\hline$p, p^{\prime}-\mathrm{DDE}$ & $0.20 * *$ & $0.20^{* *}$ & 0.08 & 0.01 & 0.19 & 1 & & & & & & \\
\hline$p, p^{\prime}-\mathrm{DDD}$ & 0.02 & 0.08 & 0.14 & $0.48 * *$ & $0.19 * *$ & $0.33 * *$ & 1 & & & & & \\
\hline$o, p^{\prime}$-DDT & 0.10 & 0.15 & 0.01 & -0.02 & 0.13 & $0.68 * *$ & $0.38 * *$ & 1 & & & & \\
\hline$p, p^{\prime}$-DDT & 0.12 & $0.47 * *$ & 0.14 & -0.01 & $0.41 * *$ & $0.63 * *$ & $0.40 * *$ & $0.56^{* *}$ & 1 & & & \\
\hline$\sum \mathrm{DDT}$ & 0.18 & $0.34 * *$ & 0.11 & 0.02 & $0.31 * *$ & $0.93 * *$ & $0.44 * *$ & $0.75 * *$ & $0.87 * *$ & 1 & & \\
\hline TOC & $0.35 * *$ & $0.27 * *$ & $0.25 * *$ & 0.03 & $0.28 * *$ & 0.19 & -0.02 & 0.08 & 0.14 & 0.19 & 1 & \\
\hline $\mathrm{pH}$ & 0.06 & 0.04 & -0.01 & $0.20 * *$ & 0.08 & 0.02 & 0.07 & 0.01 & -0.12 & -0.04 & 0.08 & 1 \\
\hline
\end{tabular}

** Correlation is significant at the 0.01 level (2-tailed)

* Correlation is significant at the 0.05 level (2-tailed) 
significant correlations between DDT concentrations and TOC content, which indicated that the residue levels were a reflection of DDTs application history and dissipation rates rather than air-soil equilibrium, which is similar to agricultural soils from Alabama, USA (Harner et al. 1999) and different from the surface soils from Tianjin, China (Gong et al. 2004).

Acknowledgments This study was supported by the National Basic Research Program of China ("973" Research Program) with Grant No.2007CB407307, the Knowledge Innovation Program of the Chinese Academy of Sciences with Grant No.KZCX2-YW-420-5, No.KZCX1-YW-06-05-02, and No.RCEES-QN-200707. The authors are grateful to Prof. K. Kannan for his suggestions for revision and English improvement.

\section{References}

Babu GS, Farooq M, Ray RS, Joshi PC, Viswanathan PN, Hans RK (2003) DDT and HCH residues in basmati rice (Oryza sativa) cultivated in Dehradun (India). Water Air Soil Pollut 144:149157. doi:10.1023/A:1022929502510

Bidleman TF, Leone AD (2004) Soil-air exchange of organochlorine pesticides in the Southern United States. Environ Pollut 128:4957. doi:10.1016/j.envpol.2003.08.034

Cai QY, Mo CH, Wu QT, Katsoyiannis A, Zeng QY (2008) The status of soil contamination by semivolatile organic chemicals (SVOCs) in China: a review. Sci Total Environ 389:209-224. doi:10.1016/j.scitotenv.2007.08.026

Cheng M (2004) Study on the concentration of phthalic acid esters and organochlorine pesticide in water body, Beijing, China(In Chinese).Master Dissertation 76

Fu S, Chu SG, Xu XB (2001) Organochlorine pesticide residue in soils from Tibet, China. Bull Environ Contam Toxicol 66:171177. doi: $10.1007 / \mathrm{s} 001280000221$

Fu JM, Mai BX, Sheng GY, Zhang G, Wang XM, Peng PA, Xiao XM, Ran R, Cheng FZ, Peng XZ, Wang ZS, Tang UW (2003) Persistent organic pollutants in environment of the Pearl River Delta, China: an overview. Chemosphere 52:411-1422. doi: 10.1016/S0045-6535(03)00477-6

Gao F, Jia JY, Wang X (2008) Occurrence and ordination of dichlorodiphenyltrichloroethane and hexachlorocyclohexane in agricultural soils from Guangzhou, China. Arch Environ Contam Toxicol 54:155-166. doi:10.1007/s00244-007-9023-3

Gong ZM, Tao S, Xu FL, Dawson R, Liu WX, Cui YH, Cao J, Wang XJ, Shen WR, Zhang WJ, Qing BP, Sun R (2004) Level and distribution of DDT in surface soils from Tianjin, China. Chemosphere 54:1247-1253. doi:10.1016/j.chemosphere.2003.10.021

Harner T, Wideman JL, Jantunen LMM, Bidleman TF, Parkhurst MJ (1999) Residues of organochlorine pesticides in Alabama soils. Environ Pollut 106:323-332. doi:10.1016/S0269-7491(99) 00110-4

Jaga K, Dharmani C (2003) Global surveillance of DDT and DDE levels in human tissues. Int J Occup Med Environ Health 16:7-20

Kannan K, Battula S, Loganathan BG, Hong CS, Lam WH, Villeneuve DL, Sajwan K, Giesy JP, Aldous KM (2003) Trace organic contaminants, including toxaphene and trifluralin, in cotton field soils from Georgia and South Carolina, USA. Arch Environ Contam Toxicol 45:30-36. doi:10.1007/s00244-002-0267-7

Kannan K, Kajiwara N, Le Boeuf BJ, Tanabe S (2004) Organochlorine pesticides and polychlorinated biphenyls in California sea lions. Environ Pollut 131:425-434. doi:10.1016/j.envpol.2004. 03.004
Li XH, Ma LL, Liu XF, Fu S, Cheng HX, Xu XB (2005) Distribution of organochlorine pesticides in urban soil from Beijing, people's republic of China. Bull Environ Contam Toxicol 74:938-945. doi:10.1007/s00128-005-0680-5

Li J, Zhang G, Qi SH, Li XD, Peng XZ (2006a) Concentrations, enantiomeric compositions, and sources of $\mathrm{HCH}$, DDT and chlordane in soils from the Pearl River Delta, South China. Sci Total Environ 372:215-224. doi:10.1016/j.scitotenv.2006.09.023

Li XH, Zhu YF, Liu XF, Fu S, Xu XB, Cheng HX (2006b) Distribution of $\mathrm{HCHs}$ and DDTs in soils from Beijing City, China. Arch Environ Contam Toxicol 51:329-336. doi: 10.1007/s00244-005-0016-9

Qiu XH, Zhu T, Jing L, Pan HS, Li QL, Miao GF, Gong JC (2004) Organochlorine pesticides in the air around the Taihu Lake, China. Environ Sci Technol 38:1368-1374. doi:10.1021/ es035052d

Shi Y, Meng F, Guo F, Lu Y, Wang T, Zhang H (2005) Residues of organic chlorinated pesticides in agricultural soils of Beijing, China. Arch Environ Contam Toxicol 49:37-44. doi:10.1007/ s00244-004-0087-z

Singh R (2001) Comparison of Organochlorine Pesticide Levels in Soil and Groundwater of Agra, India. Bull Environ Contam Toxicol 67:126-132. doi:10.1007/s001280100

Sun YZ, Wang XT, Xu XB (2005a) Persistent Organochlorine Pesticide Residues in Fish from Guanting Reservoir, People's Republic of China. Bull Environ Contam Toxicol 74:537-544. doi:10.1007/s00128-005-0617-z

Sun YZ, Wang XT, Xu XB (2005b) Studies on Levels of POPS in Main Water Bodies of Beijing and Methodology to Reduce Dioxins for China(In Chinese). Ph.D. Dissertation 73-83

Toan VD, Thao VD, Walder J, Schmutz HR, Ha CT (2007) Contamination by selected organochlorine pesticides (OCPs) in surface soils in Hanoi, Vietnam. Bull Environ Contam Toxicol 78:195-200. doi:10.1007/s00128-007-9149-z

Wang XT, Chu SG, Xu XB (2003) Organochlorine pesticide residues in water from Guanting Reservoir and Yongding River, China. Bull Environ Contam Toxicol 70:351-358. doi:10.1007/s00128002-0198-Z

Wang TY, Lu YL, Dawson RW, Shi YJ, Zhang H, Xing Y (2005a) Effects of environmental factors on organochlorine pesticide residues in soils of the Guanting Reservoir area, China. J Environ Sci Health B-Pesticides Food Contam Agric Wastes 41:309-321. doi:10.1080/03601230500357538

Wang TY, Lu YL, Shi YJ, Zhang H (2005b) Spatial distribution of organochlorine pesticide residues in soils surrounding guanting reservoir, people's republic of China. Bull Environ Contam Toxicol 74:623-630. doi:10.1007/s00128-005-0629-8

Wang TY, Lu YL, Shi YJ, Giesy JP, Luo W (2007) Organochlorine pesticides in soils around guanting reservoir, China. Environ Geochem Health 29:491-501. doi:10.1007/s10653-007-9118-9

Wu WZ, Xu Y, Schramm KW, Kettrup A (1997) Study of sorption, biodegradation and isomerization of $\mathrm{HCH}$ in stimulated sediment/water system. Chemosphere 35:1887-1894. doi: 10.1016/S0045-6535(97)00266-X

Xu DD, Dan M, Song Y, Chai ZF, Zhuang GS (2005) Concentration characteristics of extractable organohalogens in $\mathrm{PM}_{2.5}$ and $\mathrm{PM}_{10}$ in Beijing, China. Atmos Environ 39:4119-4128. doi: 10.1016/j.atmosenv.2005.03.030

Xue N, Zhang D, Xu X (2006) Organochlorinated pesticide multiresidues in surface sediments from Beijing Guanting reservoir. Water Res 40:183-194. doi:10.1016/j.watres.2005. 07.044

Zhang HB, Luo YM, Zhao QG, Wong MH, Zhang GL (2006) Residues of organochlorine pesticides in Hong Kong soils. Chemosphere 63:633-641. doi:10.1016/j.chemosphere.2005.08. 006 